\title{
KEPEDULIAN SOSIAL DALAM KITAB KELUARAN
}

\author{
Sia Kok Sin
}

\begin{abstract}
ABSTRAKSI
Kitab Keluaran seringkali dijadikan dasar teks Alkitab untuk perjuangan melawan penindasan. Kitab Keluaran juga mengungkapkan tentang kepedulian sosial kepada mereka yang membutuhkan (janda, anak yatim, orang asing dan orang miskin). Bagian yang mengungkapkan kepedulian sosial ini adalah Keluaran 22:21-27 dan 23:1-13, yang biasanya disebut "Buku Perjanjian" (Covenant Code). Bagian ini mengungkapkan perintah atau hukum Tuhan yang mendorong setiap individu orang Israel untuk peduli dengan kelompok yang membutuhkan (janda, anak yatim, orang asing dan orang miskin). Hukum atau perintah ini dapat dikatakan masih dalam bentuk yang masih "sederhana" dan belum lengkap jikalau dibandingkan dengan bagian hukum lainnya. Hukum atau perintah ini umumnya berbentuk suatu larangan. Larangan untuk melakukan tindakan-tindakan yang akan menambah penderitaan kelompok ini. Motivasi atau dasar larangan ini berdasarkan pengalaman hidup bangsa Israel sendiri dan sifat Allah. Walau masih "sederhana" dan belum lengkap, paling tidak sudah menunjukkan adanya perintah Allah kepada umat untuk menunjukkan kepedulian sosial mereka kepada kelompok yang membutuhkan.
\end{abstract}

Kata kunci: Kepedulian sosial, janda, anak yatim, orang asing, orang miskin

Kitab Keluaran merupakan salah satu kitab yang sering dikutip atau dijadikan dasar bagi perjuangan melawan penindasan. ${ }^{1}$ Perjuangan petani Jerman pada abad 17, Revolusi Amerika abad 18, permulaan sosialisme dari Marxisme abad 20 dan tentunya perjuangan politis orang Yahudi mulai zaman Makabe sampai

\footnotetext{
${ }^{1}$ Michael Walzer, Exodus and Revolution (New York: Basic Books, 1985), 5-6.
} 
gerakan Zionisme. ${ }^{2}$ Walzer mengungkapkan bahwa "the Exodus as a paradigm of revolutionary politics. ${ }^{, 3}$

Terlepas banyaknya ahli yang mengunakan sebagai teks politis, kitab Keluaran juga mengungkapkan tentang kepedulian sosial. $^{4}$ Kepedulian sosial kepada mereka yang tergolong dalam kelompok yang membutuhkan, seperti janda, anak yatim, orang miskin dan orang asing. Dalam kitab Keluaran perintah Allah kepada bangsa Israel untuk memiliki cara hidup yang memperhatikan kelompok yang membutuhkan ini dalam diketemukan dalam Keluaran 22:21-27 dan 23:1-13. Bagian ini oleh para ahli biasanya disebut "Buku Perjanjian" (Covenant Code). ${ }^{5}$ Dalam bagian ini kelompok yang membutuhkan itu terdiri dari orang asing, janda dan anak yatim, serta orang miskin.

Orang Asing (Kel. 22:21)

"Janganlah kautindas atau kautekan seorang orang asing, sebab kamupun dahulu adalah orang asing di tanah Mesir."

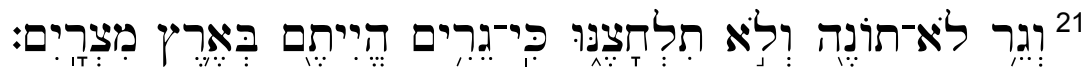

Para ahli mempunyai pendapat yang beraneka ragam tentang makna istilah "orang asing" (גֵר ) ini. Donald E. Gowan mengungkapkan bahwa istilah "orang asing" (يגר) menunjuk

\footnotetext{
${ }^{2}$ Michael Walzer, Exodus and Revolution (New York: Basic Books, 1985), 5-6.

3 Ibid., 7.

4 Jonathan P. Burnside menulis tentang Pengungsi dan Kitab Keluaran dalam, "Exodus and Assylum: Uncovering the Relationship between Biblical Law and Narrative, "JSOT, Vol.34.3 (2010), 243-266.

${ }^{5}$ Para ahli mengungkapkan bahwa hukum-hukum dalam Pentateukh terdiri dari empat bagian utama, yaitu: 10 Hukum (Kel. 20:2-27; Ul. 5:6-21) dan "Buku Perjanjian" atau Covenant Code (Kel. 20:22-23:33), Peraturan berkaitan Kemah Suci (Kel. 25-40), hukum-hukum dalam kitab Imamat, yang juga di dalamnya Holines Code (Im. 17-26) dan hukum-hukum dalam Ulangan (UI. 12-26). M.J. Selman, "Law," Dictionary of the Old Testament: Pentateuch. Editors: T.Desmond Alexander and David W. Baker (Downers Grove: InterVarsity Press, 2003), 500; W.J. Harrelson, "Law in the OT," The Interpreter's Dictionary of the Bible, K-Q (Nashville: Abingdon, 1981), 80-88.
} 
kepada orang non-Israel yang menemukan "rumah" di Israel. ${ }^{6}$ Orang asing ini mengalami situasi yang tak aman, bahaya atau sulit, oleh karena status "asingnya" itu dan mereka tidak termasuk kelompok yang mayoritas. ${ }^{7}$ Status "keasingan" umumnya menyebabkan pengalaman-pengalaman yang tak menyenangkan. ${ }^{8}$ Sedangkan John I. Durham menjelaskan nuansa makna istilah "orang asing' ini sbb: "The "newcomer," (ㄱ) as a temporary dweller, a "tourist" for a short or an extended time, was without familial and professional and sometimes national connections and so was open to abuse."

Penulis sendiri berpendapat bahwa istilah ini mempunyai makna yang mempunyai pelbagai nuansa yang khas, jika dibandingkan dengan istilah-istilah Ibrani lainnya seperti: ${ }_{1 \mathrm{~T}}$

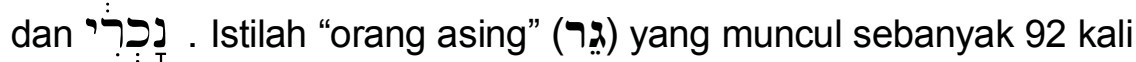
dalam Perjanjian Lama dan mempunyai beberapa hal yang penting untk dipahami, yaitu:

1. Istilah גֵ ư umumnya dikenakan kepada individu atau kelompok masyarakat yang tinggal menetap dalam jangka waktu yang cukup lama di tempat, daerah atau negara lain (asing).

2. Istilah §ֵ menunjukkan adanya pemisahan atau pembedaan dengan penduduk asli. Walaupun dֵ גapat dikatakan telah menjadi bagian komunitas suatu tempat, namun garis pemisah atau pembeda dengan penduduk asli tetaplah ada.

3. בֵา menunjuk kepada status yang khusus di suatu tempat, yaitu individu atau kelompok masyarakat yang perlu dibantu atau ditolong, namun גֵ juga menunjuk kepada kewajiban yang khusus, yaitu dituntut peraturan atau hukum kultus yang sama dengan penduduk asli.

\footnotetext{
${ }^{6}$ Donald E. Gowan, "Wealth and Poverty in the Old Testament. The Case of the Widow, the Orphan and the Sojourner," Interpretation, 41/4/1987, 343.

7 lbid., 343-4.

8 lbid., 353.

9 John I. Durham, Exodus, WBC 3 (Waco: Word Books, Publisher, 1987), 328.
} 
4. ג גר dalam Perjanjian Lama tidak mempunyai atau mengandung nuansa negatif atau berbahaya, sehingga dapat disimpulkan bahwa גֵ tidak merupakan ancaman bagi penduduk asli. ${ }^{10}$

Jadi istilah גֵ mempunyai nuansa makna yang asing, namun tidak berbahaya, menetap jangka panjang serta hampir menjadi bagian dari penduduk asli.

Dalam bagian ini Allah memerintahkan atau melarang bangsa Israel dua hal, yaitu jangan kautindas atau kautekan. Istilah

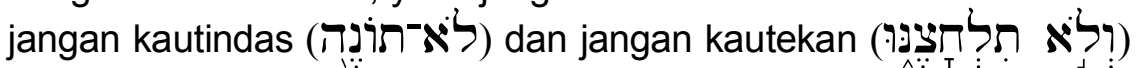
mempunyai subyek orang ke-2, maskulin, tunggal menunjukkan bahwa larangan ini ditunjukkan kepada setiap individu bangsa Israel. Perintah atau larangan bukanlah sekedar perintah yang ditujukan kepada bangsa Israel secara kolektif, tetapi kepada setiap individu bangsa Israel. Hal lain yang menarik dalam kalimat larangan ini adalah obyek kalimat ini dalam bentuk tunggal, baik yang nampak dalam kata גֵר (maskulin tunggal) atapun sufik orang

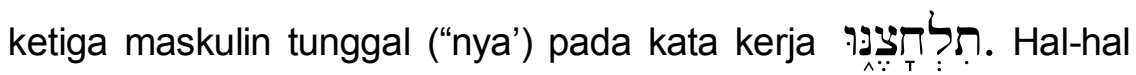
tersebut dapat menunjukkan larangan ini ditujukan kepada setiap individu bangsa Israel dalam interaksinya dengan setiap individu orang asing.

Brevard S. Childs mengungkapkan bahwa orang asing ini rapuh terhadap tindak kejahatan atau kekerasan oleh karena tidak mempunyai perlindungan dari kelompoknya (his clan). ${ }^{11}$ Oleh karena kerapuhan orang asing ini, maka Allah memerintahkan setiap individu bangsa Israel untuk tidak menindas atau menekan orang asing ini.

Larangan Allah ini didasari oleh pengalaman masa lalu bangsa Israel sebagai orang asing di Mesir. Bangsa Israel telah

\footnotetext{
${ }^{10}$ Sia Kok Sin, Keasingan Israel dan Non-Israel Dalam Kitab Ulangan serta Etnis Tionghoa di Indonesia. Disertasi. (Universitas Kristen Duta Wacana, 2008), 46-47.

${ }^{11}$ Brevard S. Childs, The Book of Exodus. OTL (Louisville: The Westminster Press, 1976), 478.
} 
tahu bagaimana menjadi orang asing atau hidup sebagai orangorang asing di Mesir. ${ }^{12}$

Janda dan Anak Yatim (Kel. 22:22-24)

${ }^{22}$ Seseorang janda atau anak yatim janganlah kamu tindas.

23 Jika engkau memang menindas mereka ini, tentulah Aku akan mendengarkan seruan mereka, jika mereka berseruseru kepada-Ku dengan nyaring.

${ }^{24}$ Maka murka-Ku akan bangkit dan Aku akan membunuh kamu dengan pedang, sehingga isteri-isterimu menjadi janda dan anak-anakmu menjadi yatim”.

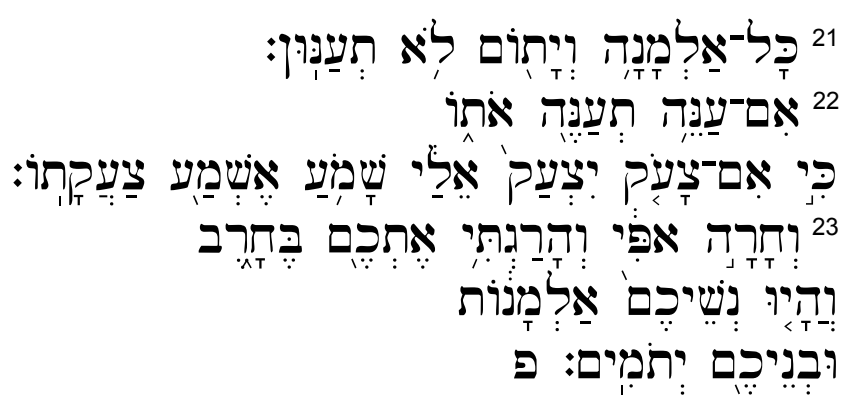

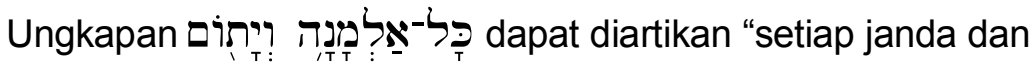
anak yatim", karena כל כל כל כל כל כitambah dengan kata benda yang tidak

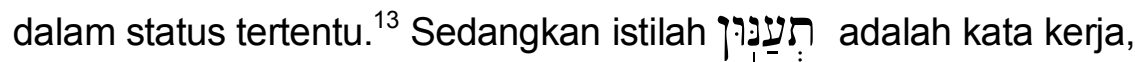
Piel, Imperative, orang ke 2, maskulin, jamak yang mana berarti janganlah kamu sekalian menindas atau merendahkan ${ }^{14}$

D. Gowan mengungkapkan dalam masyarakat yang bergantung secara utama kepada kekuatan otot manusia, keluarga yang tanpa laki-laki dewasa (janda dan anak yatim) tentu sangatlah sulit untuk dapat bertahan. ${ }^{15}$ Janda dan anak yatim mengalami

\footnotetext{
${ }^{12} \mathrm{Hal}$ ini akan dibahas lebih lanjut dalam pembahasan Kel. 23:9.

${ }^{13}$ Thomas O. Lambdin, Introduction to Biblical Hebrew (New York: Charles Scribner's Sons, 1971), 61

${ }^{14}$ Francis Brown, S.R. Driver and Charles A. Briggs, The New Brown-DriverBriggs-Gesenius Hebrew and English Lexicon (Peabody: Hendrickson Publishers, 1979), 776

${ }^{15}$ Gowan, "Wealth and Poverty in the Old Testament", 343
} 
keadaan sulit yang tak mereka rencanakan dan seringkali terjadi secara mendadak atau tiba-tiba. ${ }^{16}$ Childs mengungkapkan bahwa janda dan anak yatim ini rentan terhadap kekerasan atau penindasan, karena mereka tanpa dukungan suami atau ayah. ${ }^{17}$

Ayat 23 ini sangat menarik karena di ayat ini terdapat 3 bentuk kata kerja finit ditambah dengan infinitif absolut dari akar

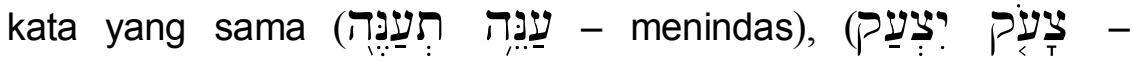

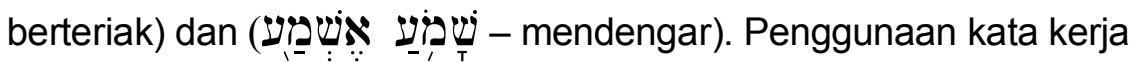
finit ditambah dengan infinitif absolut dari akar kata yang sama merupakan suatu bentuk penekanan (emphatic). ${ }^{18}$ Penindasan yang "intens" yang dilakukan mengakibatkan janda dan anak yatim ini sungguh-sungguh berteriak dan Yahweh pun sungguh-sungguh mendengar teriakan mereka. Hal ini menjadi latar belakang perintah atau larangan bagi orang Israel untuk menindas atau merendahkan janda dan anak yatim.

Ayat 24 mengungkapkan tindakan Allah yang mendengar teriakan janda dan anak yatim yang tertindas itu, yaitu Allah akan murka dan membunuh orang-orang yang menindas mereka, yang mengakibatkan keluarga para penindas itu akhirnya mengalami situasi dan kondisi yang sama dengan kondisi orang yang tertindas itu, yaitu menjadi janda dan anak yatim. Dalam kaitan dengan hal ini John I. Durham mengungkapkan:

"A cry of distress from such a defenseless person would certainly be heard by Yahweh and just as certainly provoke his furious anger, in result of which the offending Israelite would himself be slain, leaving his own wife and children in the same defenseless position as those whom he had maltreated. ${ }^{19}$

Jadi Kel. 22:22-24 mengungkapkan larangan bagi orang Israel untuk tidak menindas atau menekan janda dan yatim, oleh

\footnotetext{
${ }^{16}$ lbid., 343-4.

${ }^{17}$ Childs, The Book of Exodus., 478.

${ }^{18}$ Bill T. Arnold and John H. Choi, A Guide to Biblical Hebrew Syntax (New York: Cambridge University Press, 2003), 74-75.

${ }^{19}$ Durham, Exodus, 328.
} 
karena Allah sendiri akan menjadi hakim dan pembela bagi mereka.

\section{Orang Miskin (Kel. 22:25-27)}

25 Jika engkau meminjamkan uang kepada salah seorang dari umat-Ku, orang yang miskin di antaramu, maka janganlah engkau berlaku sebagai seorang penagih hutang terhadap dia: janganlah kamu bebankan bunga uang kepadanya.

${ }^{26}$ Jika engkau sampai mengambil jubah temanmu sebagai gadai, maka haruslah engkau mengembalikannya kepadanya sebelum matahari terbenam,

${ }^{27}$ sebab hanya itu saja penutup tubuhnya, itulah pemalut kulitnya pakai apakah ia pergi tidur? Maka apabila ia berseruseru kepada-Ku, Aku akan mendengarkannya, sebab Aku ini pengasih."

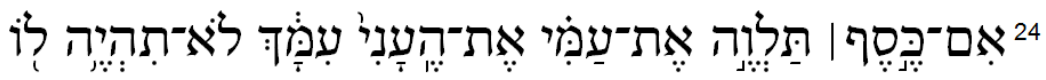

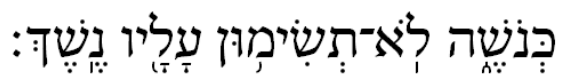

25 ${ }^{25}$

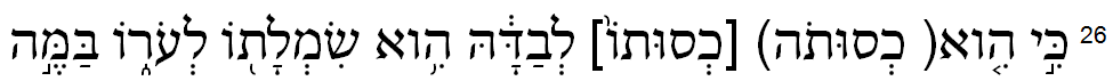

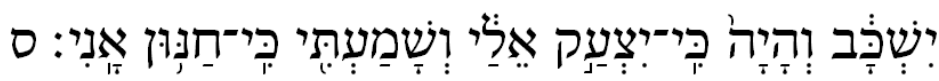

Dalam ayat 25 diungkapkan bahwa jika seseorang meminjamkan uang kepada seseorang yang miskin dari bangsa Israel, ada 2 larangan yang harus diperhatikan, yaitu:

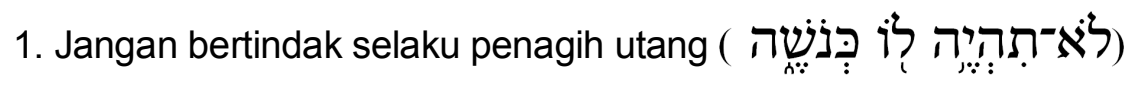

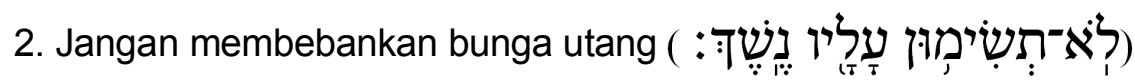

Penggunaan kata negasi (לخ) dengan kata kerja dalam bentuk imperfekt mengekspresikan suatu larangan tanpa syarat 
("an unconditional prohibition") ${ }^{20}$ atau menyatakan suatu larangan umum atau tetap (a general or permament prohibition). ${ }^{21}$ Subyek dari kedua kata kerja ini berbentuk maskulin dan tunggal. Jadi ayat ini mengungkapkan dua larangan tetap yang harus diperhatikan oleh setiap individu orang Israel dalam meminjam uang kepada orang miskin dan kedua larangan ini dapat digabungkan dalam satu larangan, yaitu jangan bertindak selaku penagih utang yang mendesak bunga kepada orang miskin yang meminjam uang.

Pembeban bunga utang merupakan sesuatu yang umum di kalangan bangsa Semit, ${ }^{22}$ tetapi dalam bagian ini jelas hal itu dilarang oleh Tuhan. Pelarangan pembebanan bunga itu hanya bagi orang Israel dan bukannya orang non-Israel. ${ }^{23}$ Roland de Vaux mengungkapkan penggunaan istilah neshek (sebuah gigitan/a bite) untuk bunga dapat diilustrasikan sbb: "Jika seorang meminjam 60 shekel, maka ia akan menerima 40 shekel dan 20 shekel adalah neshek (bunga). ${ }^{24}$ Suku bunga tahunan di Timur Tengah Kuno sangatlah tinggi, yaitu berkisar sepertiga, seperempat, seperlima atau bahkan lebih besar dari jumlah uang yang dipinjam. ${ }^{25}$ Jadi jelaslah bahwa pengenaan bunga pasti sangat memberatkan orang miskin yang meminjam uang itu.

Jadi dapat disimpulkan bahwa hukum ini mendorong agar mereka yang mempunyai kelebihan materi (kaya) tidak mengambil keuntungan kepada mereka yang kurang beruntung (miskin). ${ }^{26}$

Larangan ini diperuntukkan bagi orang miskin dari antara bangsa Israel. Dalam kaitan dengan hal ini, Durham mengungkapkan $: " .$. the one who advances the money is not to do as a businessman but as a fellow member of Yahweh's family. ${ }^{127}$ Ayat

${ }^{20}$ E. Kautzsch, Gesenius'Hebrew Grammar (Oxford: Clarendon Press, 1990), 478

${ }^{21}$ Arnold, A Guide to Biblical Hebrew Syntax, 137.

22 G.A. Barrois, "Debt, Debtor," The Interpreter's Dictionary of the Bible, A-D

(Nashville: Abingdon, 1981), 809.

23 Ibid., 809.

${ }^{24}$ Roland de Vaux, Ancient Israel, Vol. 1 (New York: McGraw-Hill Book Company, 1965), 170.

${ }^{25}$ Ibid, 171.

${ }^{26}$ M.D. Carrol R., "Wealth and Poverty," Dictionary of the Old Testament:

Pentateuch. Editors: T. Desmond Alexander and David W. Baker (Downers Grove: InterVarsity Press, 2003), 883.

${ }^{27}$ Durham, Exodus, 329. 
ini menekankan adanya perhatian khusus bagi orang miskin dari antara bangsa Israel dan bukan orang asing.

Tidak hanya pembebasan bunga, tetapi perihal jaminan (jubah) juga perlu dibebaskan. Orang Israel mengunakan dua pakaian, yaitu bagian dalam (under garment) dan luar (outer garment). Pakaian luar ini berfungsi sebagai jubah, mantel dan selimut, khususnya pada waktu udara dingin. ${ }^{28}$ Perlunya dikembalikan jubah jaminan ini sebelum matahari terbenam, agar si miskin tidak tidur kedinginan, karena tak mempunyai jubah yang menghangatkan tubuhnya. Kalau perintah ini diabaikan, sehingga si miskin ini kedinginan dan berseru-seru kepada Allah, maka Allah akan bertindak kepada si peminjam. Dasar tindakan Allah ini adalah sebab la pengasih, oleh karena itu "belas kasihan" merupakan prinsip penuntun (guiding principles) dalam bersikap terhadap keluarga umat Allah yang tak berdaya itu. ${ }^{29}$

Orang miskin seringkali tidak dapat lepas dari utang, tetapi ayat-ayat ini mengatur bagaimana utang orang miskin tidak menjadi sesuatu yang makin memperberat atau menambah penderitaan kehidupan mereka. Allah melarang setiap individu orang Israel untuk makin memperberat keadaan orang miskin oleh karena utangnya. Tindakan si pemberi utang berada dalam pantauan Allah yang penuh belas kasihan itu, yang pasti memperhatikan jeritan dari orang miskin yang tertindas.

Dalam kaitan dengan Kel. 22 ini Terence E. Fretheim membahas topik "Perhatian Allah terhadap Keadilan Sosial." ${ }^{30}$ Fretheim mengungkapkan bahwa di satu sisi Allah itu pengasih, tetapi di sisi lainnya la memberikan penghukuman yang keras kepada para penindas ini. ${ }^{31}$ la mengungkapkan: "Oppression of the poor is believed to be so heinous a crime that it carries with it the death penalty; it is a capital offense. ${ }^{\prime 32}$ Israel telah mengalami karya pertolongan Allah dari penindasan dan perbudakan Mesir,

\footnotetext{
${ }^{28}$ W.H. Grispen, Exodus. Bible Student's Commentary (Grand Rapids: Zondervan Publishing House, 1982), 224.

${ }^{29}$ Durham, Exodus, 329.

30 Terence E. Fretheim, Exodus. Interpretation (Louisville: John Knox Press, 1991), 246-250.

31 lbid., 246.

32 lbid., 246.
} 
oleh karena itu mereka diharapkan tidak meniru Mesir, tetapi mereka diperintahkan oleh Allah untuk "penyalur" keselamatan Allah kepada mereka yang 'tak beruntung" ini. ${ }^{33}$ Fretheim mengungkapkan bahwa "When the people of God mistreat the poor, they violate their own history. ${ }^{134}$ Selanjutnya Fretheim mengungkapkan:"The people of God cannot escape with a response such as, "I care about the poor."'135

Keberadaan kelompok masyarakat yang membutuhkan (janda, anak yatim, orang miskin dan orang asing) ini tidak terelakkan dalam kehidupan bangsa Israel. Kelompok ini tidak terlepas dari perhatian Allah yang memerintahkan setiap individu bangsa Israel untuk bersikap tepat terhadap kelompok ini. Perintah atau larangan dalam Keluaran 22:21-27 bertujuan agar kelompok ini tidak semakin menderita dan tertindas oleh karena kondisi mereka. Bagian teks ini tidak memberikan perintah positif bagaimana menolong kelompok yang membutuhkan ini, tetapi merupakan beberapa larangan yang mencegah bertambahnya kesulitan dan penderitaan kelompok ini.

Keluaran 23:1-13 juga mengungkapkan beberapa perintah Allah dalam kaitan dengan sikap terhadap kelompok yang membutuhkan ini, khususnya orang miskin dan orang asing.

\section{Orang Miskin}

Juga janganlah memihak kepada orang miskin dalam perkaranya. (Kel. 23:3)

$$
21
$$

Kel. 23:1-3 ini berkaitan dengan pengadilan dan penegakan keadilan dalam masyarakat. ${ }^{36}$ Dalam penanganan masalah yang terjadi, hal-hal yang harus diperhatikan dan ditegakkan adalah kejujuran, keadilan dan ketidakberpihakan terhadap siapapun.

\footnotetext{
${ }^{33}$ Fretheim, Exodus. Interpretation, 247.

34 Terence E. Fretheim, Exodus. Interpretation (Louisville: John Knox Press, 1991),247.

35 lbid., 248.

${ }^{36}$ Grispen, Exodus. Bible Student's Commentary, 226.
} 
Kata kerja dalam ayat הדר 3 mempunyai arti "menghormati" (arti positif) dan "memihak" atau "menunjukkan favoritisme" (arti negatif). ${ }^{37}$ Ayat ini mengungkapkan adanya larangan keberpihakan kepada orang miskin dalam membicarakan perkaranya. Hal ini sangat menarik. Walaupun orang miskin yang dikategorikan sebagai kelompok yang membutuhkan dan seringkali menjadi obyek penindasan kelompok lain, tidak menyebabkan mereka mempunyai hak untuk "dikhususkan". Di depan pengadilan orang miskin mempunyai kedudukan yang sama dengan kelompok masyarakat lainnya. Grispen mengungkapkan: "This law reflects psychological insight, since showing favoritism to the "lowly," the weak and the unimportant in order to gain a reputation for being a lenient judge was a great temptation..." ${ }^{138}$

Janganlah engkau memperkosa hak orang miskin di antaramu dalam perkaranya. (Kel.23:6)

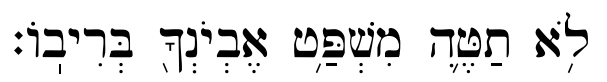

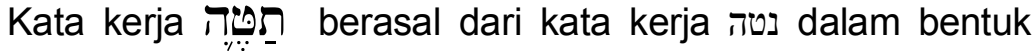
Hiphil imperfekt yang mempunyai arti merebut dengan paksa (wrest) atau menyelewengkan (pervert). Jadi kalimat

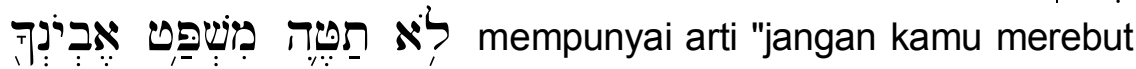
dengan paksa pengadilan orang miskin dalam perkaranya" atau "jangan kamu menyelewengkan pengadilan orang miskin dalam perkaranya". Jadi ayat ini merupakan larangan Tuhan bagi individu ("hakim") yang mengadili perkara orang miskin untuk memberikan pengadilan yang adil bagi orang miskin. Orang miskin berhak mendapatkan pengadilan yang adil. Keberadaannya sebagai orang miskin tidak boleh menghalanginya untuk mendapatkan pengadilan yang adil dalam perkaranya.

\section{Orang Asing}

Orang asing janganlah kamu tekan, karena kamu sendiri telah mengenal keadaan jiwa orang asing, sebab kamupun dahulu adalah orang asing di tanah Mesir. (23:9)

\footnotetext{
37 BDB, 213-4.

${ }^{38}$ Grispen, Exodus. Bible Student's Commentary., 226.
} 


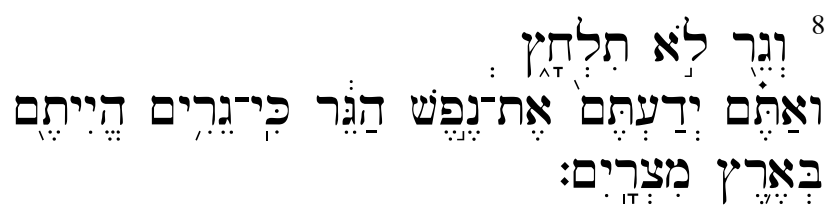

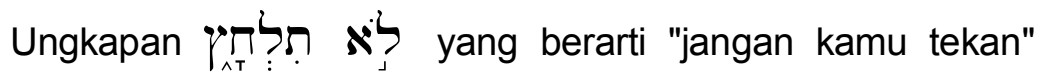
merupakan ungkapan yang sama dari Kel. 22:21. Oleh karena konteks ini berkaitan dengan pengadilan perkara, maka larangan untuk jangan menekan orang asing dapat dipahami sebagai larangan untuk memberikan pengadilan yang adil atau tanpa tindakan penekanan bagi orang asing (גר) .

Yang menarik adalah alasan larangan ini. Tuhan tidak hanya mengingatkan bahwa orang Israel (mereka) dulu adalah orang

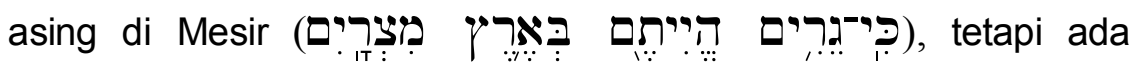
ungkapan tambahan, yaitu kamu sendiri telah mengenal keadaan

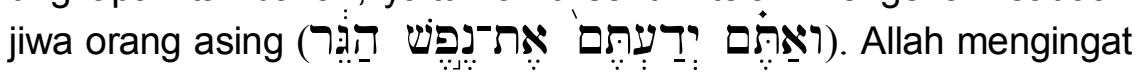
bangsa Israel bahwa mereka tidak hanya mempunyai pengalaman hidup sebagai orang asing di Mesir, tetapi mereka tahu dengan pasti bagaimana keadaan atau kondisi "yang sulit" sebagai orang asing itu. Penggunaan subyek "kamu sekalian" (אתם) dan

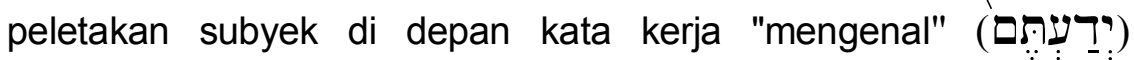
memberikan penekanan ganda. ${ }^{39}$

Larangan Allah ini didasari oleh pengalaman masa lalu bangsa Israel sebagai orang asing di Mesir. Bangsa Israel telah tahu bagaimana menjadi orang asing atau hidup sebagai orangorang asing di Mesir. Ungkapan ini tentu membangkitkan kenangan pengalaman pahit, kekerasan, penindasan dan kekejaman yang pernah alami. Paling tidak kisah perbudakan dalam Keluaran 1 dan

${ }^{39} \mathrm{P}$. Joüon and Muraoka mengungkapkan tentang penambahan subyek pada kata kerja finit sbb: "Since a finite verb by itself indicates the person, it can be said that, whenever a verb occurs with a pronoun referring to its subject, some extra nuance is intended. Generally speaking, the addition of a pronoun gives some special prominence to the person or persons indicated byt it, comprable to a close up focus in photography."

P. Joüon and T. Muraoka, A Grammar of Biblical Hebrew (Roma: Gregorian \& Biblical Press, 2013), 505. Begitu juga urutan Subyek yang mendahului Predikat memberikan suatu penekan. Ibid., 546. 
2 dengan mudahnya dapat mereka ingat. Grispen mengungkapkan: "The Israelite could enter into the feeling (lit. "soul") of the alien because of their own experience. ${ }^{140}$

Dasar larangan atau perintah Allah ini sangat menarik untuk direnungkan. Pengalaman pahit masa lalu justru dijadikan motivasi atau dasar untuk tidak melakukan kejaharan yang sama yang pernah mereka alami. Pengalaman penindasan dan penekanan yang bangsa Israel alami menjadi dasar untuk tidak menindas dan menekan orang asing. Pengalaman pahit atau buruk yang justru memperkaya kehidupan mereka dengan memperlakukan sesama mereka lebih baik.

\section{Tahun Sabat}

${ }^{10}$ Enam tahunlah lamanya engkau menabur di tanahmu dan mengumpulkan hasilnya, ${ }^{11}$ tetapi pada tahun ketujuh haruslah engkau membiarkannya dan meninggalkannya begitu saja, supaya orang miskin di antara bangsamu dapat makan, dan apa yang ditinggalkan mereka haruslah dibiarkan dimakan binatang hutan. Demikian juga kaulakukan dengan kebun anggurmu dan kebun zaitunmu. (23:10-11)

Tahun ketujuh ini biasanya disebut sebagai Tahun Sabat, yang mana bangsa Israel diperintahkan untuk membiarkan ladang mereka untuk tidak ditanami atau dipanen dalam tahun ini, yang mana hal ini memberikan kesempatan untuk orang miskin dan binatang hutan dapat mengambil dan memakan hasil ladang. ${ }^{41} \mathrm{Hal}$ yang sama juga diungkapkan oleh Roland de Vaux: "According to the Code of the Covenant again, the fields, vineyards and olive groves are to lie fallow every seventh year and their produce is to be left for the poor (Ex. 23:10-11)"." Durham menambahkan: "Whatever the land produces on its own, the "volunteer crop" which comes through no effort of cultivation, the poor of the land are to have, and anything the leave, the wild animals are not to be deterred from eating. ${ }^{\text {A3 }}$ Jadi pemberian hukum tahun Sabat yang

\footnotetext{
${ }^{40}$ Grispen, Exodus. Bible Student's Commentary., 229.

41 lbid., 229-30.

42 de Vaux, Ancient Israel, Vol. 1, 172.

${ }^{43}$ Durham, Exodus, 329.
} 
mana perlu dihayati oleh bangsa Israel dapat merupakan sarana memberikan pertolongan bagi orang miskin.

\section{Hari Sabat}

12 Enam harilah lamanya engkau melakukan pekerjaanmu, tetapi pada hari ketujuh haruslah engkau berhenti, supaya lembu dan keledaimu tidak bekerja dan supaya anak budakmu perempuan dan orang asing melepaskan lelah. (23:12)

Penghayatan hari Sabat oleh bangsa Israel menyebabkan tersedianya waktu istirahat tidak hanya bagi orang Israel saja, tetapi bagi budak, orang asing ataupun binatang. ${ }^{44}$ Penghayatan hari Sabat yang memberikan manfaat bagi kemanusiaan. ${ }^{45}$

\section{KESIMPULAN}

1. Bagian kitab Keluaran yang mengungkapkan perintah Allah kepada bangsa Israel untuk memiliki cara hidup yang memperhatikan kelompok yang membutuhkan ini (janda, anak yatim, orang asing dan orang miskin) terdapat dalam Kel. 22:2127 dan 23:1-13 yang biasanya disebut oleh para ahli sebagai "Buku Perjanjian" (Covenant Code). W.J. Harelson mengungkapkan bahwa bagian ini merupakan the older legal tradition. $^{46}$ Oleh karena itu tidaklah mengherankan jikalau bagian ini tidak memberikan petunjuk yang lengkap tentang cara hidup atau sikap terhadap janda, anak yatim, orang asing dan orang miskin. ${ }^{47}$

2. Perintah tentang kepedulian sosial dalam kitab Keluaran ini mempunyai umumnya berbentuk suatu larangan. Perintah Tuhan kepada bangsa Israel ini umumnya berbentuk larangan (“Janganlah ..."). Tiar Ramon dalam artikelnya tentang "Pengantar IImu Hukum" mengungkapkan: "Perintah, yang merupakan keharusan bagi seseorang untuk berbuat sesuatu

\footnotetext{
${ }^{44}$ Ibid., 329.

${ }^{45}$ Fretheim, Exodus, 250.

${ }^{46}$ W.J. Harrelson, "Law in the OT," The Interpreter's Dictionary of the Bible, 80.

${ }^{47}$ Kalau hal ini dibandingkan dengan hukum-hukum dalam kitab Imamat dan Ulangan.
} 
oleh karena akibat2nya dipandang baik. Larangan, yang merupakan keharusan bagi seseorang untuk tidak berbuat sesuatu oleh karena akibat-akibatnya dipandang tidak baik."48 Jadi dapat disimpulkan bahwa kepedulian sosial dalam kitab Keluaran merupakan keharusan-keharusan yang paling dasar dan belum menunjuk kepada suatu tindakan yang aktif untuk mengentaskan kelompok yang membutuhkan ini (janda, anak yatim, orang asing dan orang miskin) untuk menjadi kelompok atau pribadi yang mandiri. Larangan-larangan ini bertujuan agar kelompok ini tidak makin terpuruk dalam kesulitan dan penderitaan mereka.

3. Perintah tentang kepedulian sosial dalam kitab Keluaran ini memberikan penekanan pada individu. Larangan Tuhan ini ditujukan kepada setiap individu bangsa Israel, oleh karena umumnya larangan ini mempunyai subyek tunggal (kecuali. Kel. 22:22). Obyek dalam larangan-larangan ini juga berbentuk tunggal. Hubungan antara subyek yang tunggal dan Obyek yang berbentuk tunggal dalam larangan-larangan yang diberikan Tuhan menunjuk kepada interaksi antar pribadi. Larangan ini dalam konteks setiap individu bangsa Israel berinteraksi dengan setiap individu dari janda, anak yatim, orang asing dan orang miskin.

Hal ini berbeda dengan konsep umum di dunia Timur Dekat Kuno. Melalui penyelidikan topik "Janda, Yatim dan Orang Miskin" dalam Perjanjian Lama dan literatur di luar Alkitab (Extra-Biblical Literature), ${ }^{49}$ Richard D. Patterson menyimpulkan bahwa dalam naskah kuna Mesopotamia, Mesir dan SyroPalestine tugas untuk memperhatikan janda, yatim dan orang miskin merupakan tugas seorang raja. ${ }^{50}$ Sedangkan dalam Perjanjian Lama tugas memperhatikan kelompok itu tidak hanya menjadi tugas seorang raja, tetapi juga menjadi cara hidup yang diharapkan dalam struktur sosial Israel. ${ }^{51}$

\footnotetext{
${ }^{48}$ http://tiarramon.wordpress.com/2009/05/11/ilmu-hukum/ diakses 23 Juli 2014 pk. 7.52

${ }^{49}$ Richard D. Patterson, "The Widow, the Orphan and the Poor in the Old Testament and the Extra-Biblical Literature", Bibliotheca Sacra, July 1973, 223-34. 50 lbid., 228.

${ }^{51}$ Richard D. Patterson, "The Widow, the Orphan and the Poor in the Old Testament and the Extra-Biblical Literature", Bibliotheca Sacra, July 1973,228
} 
Kitab Keluaran ini belum membahas tentang seluk beluk raja dan tanggung jawabnya. Kitab Keluaran umumnya memberikan penekanan pada tanggung jawab setiap individu dalam interaksinya dengan setiap individu dari janda, anak yatim, orang asing dan orang miskin.

4. Melalui penyelusuran terhadap hukum-hukum ini dapat ditemukan dua motivasi atau dasar hukum atau larangan ini, yaitu pengalaman hidup bangsa Israel sendiri dan sifat Allah. Donald E. Gowan mengungkapkan: "The basis for that is partly their common humanity as they share the same feelings, but is primarily because these people have dignity in the sight of Yahweh. ${ }^{152}$ Individu bangsa Israel diperintahkan untuk peduli kepada orang asing, oleh karena mereka sendiri telah mengalami dan merasakan kehidupan sebagai orang asing. Individu bangsa Israel diperintahkan untuk peduli kepada orang miskin oleh karena Allah adalah pengasih yang mendengar jeritan penderitaan orang miskin yang tertindas.

5. Penghayatan Hari Sabat dan Tahun Sabat secara tidak langsung juga merupakan wujud kepedulian terhadap kelompok yang membutuhkan ini. Melalui Hari Sabat kelompok ini dapat menikmati istirahat dari tanggung jawab pekerjaan mereka, sedangkan melalui Tahun Sabat kelompok ini dapat menikmati hasil ladang yang sengaja tidak dipanen.

Jadi dapat disimpulkan bahwa kitab Keluaran mengungkapkan perintah atau hukum Tuhan yang mendorong bangsa Israel (khususnya individu) untuk peduli dengan kelompok yang membutuhkan (janda, anak yatim, orang asing dan orang miskin). Hukum atau perintah ini dapat dikatakan masih dalam bentuk yang masih "sederhana" dan belum lengkap jikalau dibandingkan dengan bagian hukum lainnya. Hukum atau perintah ini umumnya berbentuk suatu larangan. Walau masih "sederhana" dan belum lengkap, paling tidak sudah menunjukkan adanya perintah Allah kepada umat untuk menunjukkan kepedulian sosial mereka kepada kelompok yang membutuhkan. Motivasi atau dasar larangan ini berdasarkan pengalaman hidup bangsa Israel sendiri dan sifat Allah.

52 Gowan, "Wealth and Poverty in the Old Testament," 352. 


\section{DAFTAR KEPUSTAKAAN}

Arnold, Bill. T, John H. Choi. A Guide to Biblical Hebrew Syntax (New York: Cambridge University Press, 2003)

Barrois, G.A., "Debt, Debtor," The Interpreter's Dictionary of the Bible, A-D (Nashville: Abingdon, 1981)

Brown, Francis, S.R. Driver and Charles A. Briggs, The New Brown-Diriver-Briggs- Gesenius Hebrew and English Lexicon (Peabody: Hendrickson Publishers, 1979)

Burniside, Jonathan P., "Exodus and Assylum: Uncovering the Relationship between Biblical Law and Narrative," JSOT, Vol. 34.3 (2010)

Carrol R., M.D., "Wealth and Poverty," Dictionary of the Old Testament: Pentateuch. Editors: T. Desmond Alexander and David W. Baker (Downers Grove: InterVarsity Press, 2003)

Childs, Brevard S. The Book of Exodus. OTL (Louisville: The Westminster Press, 1976)

de Vaux, Roland. Ancient Israel (New York: McGraw-Hill Book Company, 1965)

Durham, John I. Exodus, WBC 3 (Waco: Word Books, Publisher, 1987)

Fretheim, Terence E., Exodus. Interpretation (Louisville: John Knox Press, 1991)

Gowan, Donald. E., "Wealth and Poverty in the Old Testament. The Case of the Widow, the Orphan and the Sojourner," Interpretation, 41/4/1987

Grispen, W.H. Exodus. Bible Student's Commentary (Grand Rapids: Zondervan Publishing House, 1982)

Harrelson, W.J., "Law in the OT," The Interpreter's Dictionary of the Bible, K-Q (Nashville: Abingdon, 1981) 
Joüon P. and T. Muraoka, A Grammar of Biblical Hebrew (Roma: Gregorian \& Biblical Press, 2013)

Kautzch, E. Gesenius' Hebrew Grammar (Oxford: Clarendon Press, 1970)

Lambdin, Thomas O. Introduction to Biblical Hebrew (New YorkL Charles Schribner's Sons, 1971)

Patterson, Richard D., "The Widow, the Orphan and the Poor in the Old Testament and the Extra-Biblical Literature," Bibliotheca Sacra, July, 1973

Ramon, Tiar., "Pengantar IImu Hukum," http://tiarramon.wordpress.com/2009/05/11/ilmu-hukum/ diakses 23 Juli 2014

Selman, M.J., "Law," Dictionary of the Old Testament: Pentateuch. Editors: T. Desmond Alexander and David W. Baker (Downers Grove: InterVarsity Press, 2003)

Sia, Kok Sin, Keasingan Israel dan Non-Israel Dalam Kitab Ulangan serta Etnis Tionghoa di Indonesia. Disertasi, Universitas Kristen Duta Wacana, 2008

Walzer, Michael, Exodus and Revolution (New York: Basic Books, 1985) 